\title{
Different Faces of Fas Signaling in Cancer Cells
}

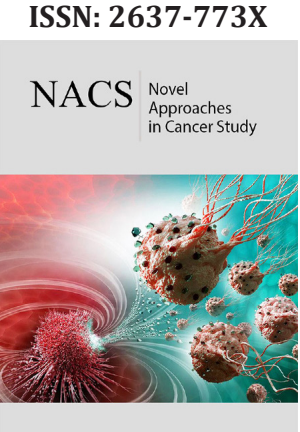

*Corresponding author: Magdalena Szaryńska, Debinki 1, 80-210, Gdansk, Poland

Submission: 毕 September 10, 2019

Published: 海September 16, 2019

Volume 3 - Issue 2

How to cite this article: Magdalena $\mathrm{S}$, Agata O K. Different Faces of Fas Signaling in Cancer Cells. Nov Appro in Can Study. 3(2). NACS.000559.2019.

DOI: 10.31031/NACS.2019.03.000559

Copyright@ Magdalena Szaryńska, This article is distributed under the terms of the Creative Commons Attribution 4.0 International License, which permits unrestricted use and redistribution provided that the original author and source are credited.

\author{
Magdalena Szarynska* and Agata Olejniczak Kęder \\ Department of Histology, Poland
}

\begin{abstract}
Fas signaling pathway is known to be engaged in elimination of unwanted cells by apoptosis, however, new discoveries presented its alternate face, namely FasR and FasL play pro-cancerous functions facilitating cancer progression, invasion and metastasis. Here, we provide a brief summary of knowledge concerning Fas signaling pathway merits and disadvantages in cancer. Fas molecules were found to be engaged in many pathways induced by different therapeutic compounds, such as aspirin and antibiotics. This suggest that Fas signaling pathway may be employed as adjuvant factor for immunotherapy of variable design. Although, the literature presents some first optimistic results, we must intensify efforts to finally introduce Fas-associated procedures into standard therapeutic options.
\end{abstract}

\section{Introduction}

The Fas signaling is known to exert very variable effects in wide spectrum of cells. The FasR/ FasL (CD95/ CD95L) proteins can be associated with both positive (physiological) and negative (pathological) effects. Nowadays, there is a growing interest in the elucidation of the Fas signaling role in the pathogenesis and progression of various cancers. Additionally, it was proven that the expression of FasR/ FasL in colorectal cancer is associated with worse prognosis, metastasis and recurrence [1-6] the aspects of cancer biology which cancer stem cells are responsible for [7]. On the one hand, Fas signaling pathway is considered as a potential target for anticancer therapy and, on the other hand, is hoped to be exploit as therapeutic tool. The approach to this issue is dynamically update since the state of knowledge concerning Fas signaling functions is rapidly developing. The most established pro-apoptotic activity of FasR/L signaling is the elimination of non-CSC cancerous, virus-infected or useless/ autoreactive T cells by cytotoxic T lymphocytes [8]. Drug therapy combining the multi-kinase inhibitor Sorafenib and the histone deacetylase inhibitor Vorinostat was shown to activate Fas-mediated apoptosis by promoting receptor tyrosine phosphorylation or contribution to FasR activation via initial facilitation of ROS generation and subsequent FasL expression [9]. Additionally, Fas signaling was proven to be associated with HSPs. Although it was originally demonstrated in rat global brain ischemia model, we assume that similar relationships exist in cancer cells as well. Inhibition of HSP90 proteins reduced FasL expression and induced neuroprotective effect [10]. Moreover, the heat shock proteins accumulation was demonstrated as a specific mechanism increasing protein stability and reducing a turnover during Fas-mediated apoptosis in Jurkat cells [11].

The expression of FasR/ FasL by cancer cells implies that they are themselves resistant to Fas-mediated apoptosis [8]. One of the mechanisms used by the cancer cells to acquire insensitivity to pro-apoptotic signals is elimination (or rather prominent reduction) of the FasR from their surface what disrupts the expression of factors engaged in apoptosis [1214]. This is so called "cancer evasion mechanism" [15]. It claims that tumor cells escape from immune cells attack and attract (or kidnap) immune elements for their own good. The decreased FasR level diminished the apoptosis probability, but the level of FasR in cancer cell membranes necessary for their survival was estimated to be 1000-times lower than the level required for its pro-apoptotic signaling [16]. The current observations regarding cancer cells expression of FasR and their resistance to apoptosis induction suggest that Fas signaling molecules play also non-apoptotic functions within cancer tissue $[17,18]$. The observed prosurvival activity of Fas signaling for normal stem cells homeostasis and embryogenesis of the nervous system [16, 19-22] suggested that Fas signaling pathway may also have a nonapoptotic function in cancer stem cells (CSCs) [23].

The group of Marcus Peter showed that the elimination of either FasR or FasL causes death of cancer cells (in vitro and in vivo) through a process termed DICE (death induced 
by CD95 or CD95L elimination). DICE is a necrotic form of mitotic catastrophe characterized by cell swelling, ROS production causing DNA damage and activation of caspase-2 following mitochondrial outer membrane permeabilization [8,24]. During DICE many different pathways directing cells to death were proved to be stimulated thus it is hardy possible to modulate that process. These observations proved that DICE is a naturally occurring antitumor defense mechanism, which can eliminate cancer cells devoid of FasR. The pro-survival activity of FasR is believed to be mostly relevant to cancer cells, since cancer cells rarely or even never have mutated or deleted both alleles of FasR. Additionally, it was shown that none of the normal tissues during embryonic development in FASR/ FASL knockout mice showed a growth defects or signs of cell death $[8,24]$. Based on the evidence from both FasL and FasR knockdown mice that did not show any signs of cell death or growth deficiencies in any tissue outside the immune system, it was predicted that DICE preferentially affects cancer cells (especially CSCs) with little effect on normal cells [8,24].

In spite of such optimistic results of experiments conducted on genetically modified animals [8,24], mice injected with agonistic anti-FasR antibodies died after their INK and c-Jun had become phosphorylated [16]. With regard to all these observations, the clinical application of Fas-mediated procedures raise huge controversies because of major side effects, for instance massive apoptosis induced in the liver [25]. In our previous work, we found significant positive correlations between FasR expression and some CSC-like markers, what seemed to indicate the cancer progression promoting role of FasR/ FasL signaling [26]. We demonstrated increased expansion of $\mathrm{CD} 133^{+}$cells within colonospheres following FasR stimulation, indicating specific clonal selection of cells sensitive to Fas-mediated supporting treatment. We also found that adherent HCT116 and HT29 CRC lines cells markedly decreased their proliferation rate not associated with increased apoptosis after during the incubation with anti-FasR agonistic antibody. That suggested the engagement of FasR in the senescence induction accompanied by the cell cycle arrest as was earlier presented by Raats et al. [27]. Additionally, these observations not necessarily were associated with particular genetic features of cancer cells (such as KRAS mutations). Fas signaling pathway was found to be engaged in ASA-mediated anti-cancerous effect. Chen et al. [28] described that ASA could induce apoptosis in Cox-independent way through p300-AcH3K9-FasL axis, which specifically targets CSCs. However, many crucial aspects concerning CSCs were left open. Unfortunately, authors did not mention nor evaluated any other possible effects which could be triggered by Fas pathway, including DICE. The literature and our previous data proved that thorough analysis of Fas signaling functions for CRC progression can be a source of very interesting discoveries, crucial for Fas associated procedures application. It seems to be extremely valuable, since CSCs were evidenced to be unusually sensitive to FasR/ FasL-based procedures [18,29]. However, much needs to be learned before these new therapeutic options can be applied in human cancer.

\section{References}

1. Ste Marie R, Wang TC, Lyle S, Kurt-Jones E, Houghton J, et al. (2009) Human and mouse colon cancer utilizes CD95 signaling for local growth and metastatic spread to liver. Gastroenterology 137(3): 934-944.

2. Hoogwater FJ, Nijkamp MW, Smakman N, Steller EJ, Emmink BL, et al. (2010) Oncogenic K-Ras turns death receptors into metastasispromoting receptors in human and mouse colorectal cancer cells. Gastroenterology 138(7): 2357-2367.

3. Kykalos S, Mathaiou S, Karayiannakis AJ, Patsouras D, Lambropoulou, et al. (2012) Tissue expression of the proteins fas and fas ligand in colorectal cancer and liver metastases. Journal of Gastrointestinal Cancer 43(2): 224-228.

4. Nijkamp MW, Hoogwater FJ, Steller EJ, Westendorp BF, vander Meulen TA, et al. (2010) CD95 is a key mediator of invasion and accelerated outgrowth of mouse colorectal liver metastases following radiofrequency ablation. Journal of Hepatology 53(6): 1069-1077.

5. Strater J, Hinz U, Hasel C, Bhanot U, Mechtersheimer G, et al. (2005) Impaired CD95 expression predisposes for recurrence in curatively resected colon carcinoma: clinical evidence for immunoselection and CD95L mediated control of minimal residual disease. Gut 54(5): 661665 .

6. Zhang W, Ding EX, Wang Q, Zhu DQ, He J, et al. (2005) Fas ligand expression in colon cancer: a possible mechanism of tumor immune privilege. World Journal of Gastroenterology 11(23): 3632-3635.

7. Frank NY, Schatton T, Frank MH (2010) The therapeutic promise of the cancer stem cell concept. The Journal of Clinical Investigation 120(1): 41-50.

8. Peter ME, Hadji A, Murmann AE, BrockwayS, PutzbachW,et al. (2015) The role of CD95 and CD95 ligand in cancer. Cell Death Differentiation 22(4): 549559.

9. Park MA, Reinehr R, Haussinger D, Voelkel-Johnson C, Ogretmen B, et al. (2010) Sorafenib activates CD95 and promotes autophagy and cell death via Src family kinases in gastrointestinal tumor cells. Mol Cancer Ther 9(8): 2220-2231.

10. Yin XH, Han YL, Zhuang Y, Yan JZ, Li C, et al. (2017) Geldanamycin inhibits Fas signaling pathway and protects neurons against ischemia. Neurosci Res 124: 33-39.

11. Concannon CG, Holmberg CI, Szegezdi E, Sistonen L, Samali A, et al. (2005) CD95-mediated alteration in Hsp70 levels is dependent on protein stabilization. Cell Stress Chaperones 10(1): 59-65.

12. Ivanov VN, Lopez Bergami P, Maulit G, Sato TA, Sassoon D, et al. (2003) FAP-1 association with Fas (Apo-1) inhibits Fas expression on the cell surface. Molecular and Cellular Biology 23: 3623-3635.

13. Ivanov VN, Ronai Z, Hei TK (2006) Opposite roles of FAP-1 and dynamin in the regulation of Fas (CD95) translocation to the cell surface and susceptibility to Fas ligand-mediated apoptosis. The Journal of Biological Chemistry 281(3): 1840-1852.

14. Igney FH, Krammer PH (2005) Tumor counterattack: Fact or fiction. Cancer Immunology Immunotherapy 54(11): 1127-1136.

15. Legitimo A, Consolini R, Failli A, Orsini G, Spisni R, et al. (2014) Dendritic cell defectsin the colorectal cancer. Human Vaccines Immunotherapeutic 10(11): 3224-3235.

16. Chen L, Park SM, Tumanov AV, Hau A, Sawada K, et al. (2010) CD95 promotes tumour growth. Nature 465(7297): 492-496, 2010.

17. Steller EJ, Ritsma L, Raats DA, Hoogwater FJ, Emmink BL, et al. (2011) The death receptor CD95 activates the cofilin pathway to stimulate tumour cell invasion. EMBO Rep 12(9): 931-937. 
18. Teodorczyk M, Kleber S, Wollny D, Sefrin JP, Aykut B, et al. (2015) CD95 promotes metastatic spread via Sck in pancreatic ductal adenocarcinoma. Cell Death Differ 22(7): 1192-1202.

19. Martin-Villalba A,Llorens-Bobadilla E,WollnyD (2013) CD95 in cancer: tool or target. Trends in Molecular Medicine 19(6): 329-335.

20. Desbarats J, Newell MK (2000) Fas engagement accelerates liver regeneration after partial hepatectomy. Nature Medicine 6(8): 920-923.

21. Desbarats J, Birge RB, Mimouni RM, Weinstein DE, Palerme JS, et al. (2003) Fas engagement induces neurite growth through ERK activation and p35 upregulation. Nature Cell Biology 5(2): 118-125.

22.Zuliani C, Kleber S, Klussmann S, Wenger T, Kenzelmann M, et al. (2006) Control of neuronal branching by the death receptor CD95 (Fas/Apo-1) Cell Death and Differentiation 13(1): 31-40.

23. Corsini NS, Sancho-Martinez I, Laudenklos S, Glagow D, Kumar S, et al. (2009) The death receptor CD95 activates adult neural stem cells for working memory formation and brain repair. Cell Stem Cell 5(2): 178190, 2009.

24. Hadji A, Ceppi P, Murmann AE, Brockway S, Pattanayak A, et al. (2014) Death induced by CD95 or CD95 ligand elimination. Cell Reports 7(1): 208-222.
25. Ogasawara J, Fukunaga RW Adachi M Matsuzawa A, Kasugai T, et al. (1993) Lethaleffectoftheanti-Fasantibodyin mice. Nature 364(6440): 806-809.

26. Szarynska M, Olejniczak A, Wierzbicki P, Kobiela J, Laski D et al. (2017) FasR and FasL in colorectal cancer. International Journal of Oncology 51(3): 975-986.

27. Raats DA, Frenkel N, van Schelven SJ, Rinkes IH, Laoukili J, et al. (2017) CD95 ligand induces senescence in mismatch repair-deficient human colon cancer via chronic caspase-mediated induction of DNA damage. Cell Death and Disease.

28. Chen Z, Li W, Qiu F, Huang Q, Jiang Z, et al. (2018) Aspirin cooperates with p300 to activate the acetylation of H3K9 and promote FasL-mediated apoptosis of cancer stem-like cells in colorectal cancer. Theranostics 8(16): 4447-4461.

29. Szarynska M, Olejniczak A, Kmiec Z (2016) The role of cancer stem cells in pathogenesis of colorectal cancer. Postepy Higienyi Medycyny Doswiadczalnej 70: 1469-1482. 